UCRL -94335

DE86 012192

\title{
ECONOMIC STUDIES FOR HEAVY-ION-FUSION \\ ELECTRIC POWER PLANTS
}

Wayne R. Meler

Williem J. Hogan

Roger 0. Bengerter

This paper was prepared for submittal to the

International Symposium on Heavy Ion Fusion

Washington, D.C

May $27-29,1986$

May 20, 1986

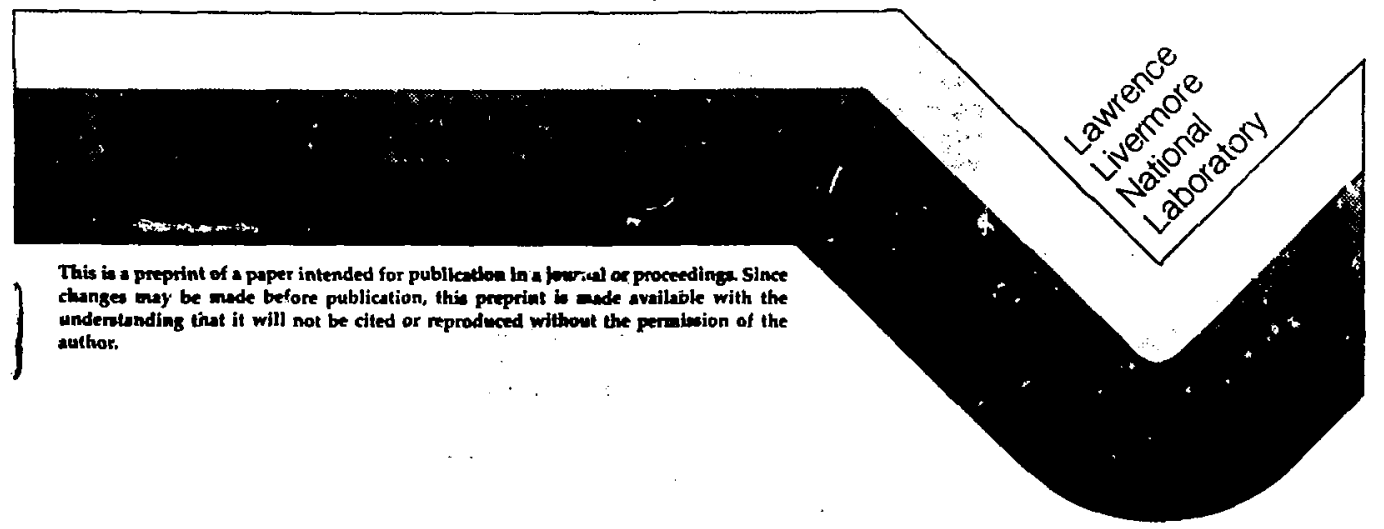


Wayne R. Meier, William 3. Hogan, Roger 0. Bangerter

Lawrence Livermore National Laboratory

Livermore, CA 94550

\section{AESTRACT}

We have conducted parametric economic studies for heavy-ionfusion electric power plants. We examined the effects on the cost of electricity of several design parameters: cost and cost scaling for the reactor, driver, and target factory; maximum achievable chamber pulse rate; target gain; electric conversion efficiency; and net electric power. Using the most recent estimates for the heavy-ion-driver cost along with the Cascade reactor cost and efficiency, we found that a 1.5 to 3 GWe heavy-iori-fusion power plant, with a pulse rate of $5-10 \mathrm{~Hz}$, can be competitive with nuclear and cual power plants.

\section{INTRODUCTION}

The Heavy-jon-fusion Si:stems Assessment Project has produced new estimates of the capitil cost and performance of an induction linac accelerator for inertial fusion. 1 These estimates have been incorporated in an economic model of a heavy-ion-fusion (HIF) electric power plant. This model has been used to do parametric studies to identify the features of the plant that have the highest leverage for improving KIF economics. One of the factors that will be used to judge the desirability of an ICF power plant is its economic competitiveness compared $t J$ other power sources, and one of the several figures of merit for economic competitiveness is the projected cosi of electricity (COE). While we caution against using any of the COEs calculated in this paper in an absolute sense, we believe the results are useful in relative comparisons. The model should primarily be used to identify the technical developments that would lead to the greatest reduction in COE. The model can also be used (if a great deal of care is taken) to grossly compare HIF to other future pawer sources. The same economic assumptions must be used in the comparison. This paper updates our previous analyses of HIF economics. 2,3

\section{COST AND PERFORMANCE MODELS}

The COE in $t / \mathrm{kW}_{\mathrm{e}} \mathrm{h}$ is given by

$$
\mathrm{COE}=\left(\mathrm{RC}_{\mathrm{T}}+\mathrm{M}+\mathrm{F}\right) ;\left(0.0876 \mathrm{a} \mathrm{P}_{\mathrm{n}}\right) \text {, }
$$

*Work performed under the auspices of the U.S. DOE by the Lawrence Livermore National Laboratory under Contract No. W-7405-ENG-38. 
where $R=$ annual fixed charge rate $\left(\mathrm{yr}^{-1}\right)$,

$C_{T}=$ total capital cost of the plant $(\$ B)$,

$M=$ annual operation and maintenance cost (\$B),

$F=$ annual fuel cycle cost (\$B),

$\alpha=$ plant avallability factor, and

$P_{n}=$ net electric power $\left(G W_{e}\right)$.

The evaluation of this expression for future fission and coal plants is discussed at length in the Nuclear Energy Cost Data Base. 4 Based on the methods and financlal parameters given in Ref. 4, the constant dollar fixed charge rate we use is $8.3 \%$. We assume that the annual fuel cost is negligible, and that the O\&M cost is $3 \%$ of $\mathrm{C}_{T}$. Thus, the numerator of $\mathrm{Eq}$. 1 is equal to $0.113 \mathrm{C}_{\mathrm{T}}$. The total capital cost $1 \mathrm{~s} 1.83 \mathrm{times}$ the direct capital cost. This factor includes home and field office construction and engineering services, owner's cost, a project contingency, and interest during construction in constant dollars. The ratio of total capital cost to direct capital cost (1.83) is midway between the value for coal plants $(1.53)$ and the value for nuclear plants with the best experience in holding down costs $(2.07)$. (The average ratio for fission plants is significantly higher at 2.75)

The capital cost of the power plant is broken into three items; the reactor, the driver and the target factory.

$$
\mathrm{C}_{\mathrm{T}}=1.83\left(\mathrm{C}_{\mathrm{Td}}+\mathrm{C}_{\mathrm{dd}}+\mathrm{C}_{\mathrm{tfd}}\right)
$$

where $\mathrm{C}_{I d}, \mathrm{C}_{d d}$, and $\mathrm{C}_{t f d}$ are the direct capital costs of the reactor, driver and target factory, respectively.

\section{Reactor Cost}

The cost of the reactor, which includes the the fusion chamber and balance of plant, is based on the recent cost estimate for the Cascade reactor. 5 The Cascade reference design has an estimated direct capital cost of $\$ 3.66 \mathrm{~B}$ at a plant thermal power of 1.67 $\mathrm{GW}_{\mathrm{t}}$ and a gross electric power of $0.905 \mathrm{GW}_{\mathrm{e}}$. The auxiliary power requirement of the Cascade plant are $1.7 \%$ of the gross electric power. The direct capital cost can be scaled to other sizes by

$$
\mathrm{C}_{\mathrm{rd}}=\mathrm{C}_{\mathrm{r}}\left(\mathrm{P}_{\mathrm{t}} / 1.67\right)^{\mathrm{a}}\left(0.72 \mathrm{~N}_{\mathrm{U}}+0.28\right) \quad \$ \mathrm{~B}
$$

where $C_{r}$ is reactor cost coefficient $(\$ B), P_{t}$ is thermal power $\left(G W_{t}\right)$, a is the power scaling exponent, and $N_{U}$ is the number of reactor units (i.e., chamber, structures, and associated balance of plant equipment) in the plant. The reference case scaling exponent is 0.49 . The last term accounts for savings in both direct and indirect costs when more than one unit is built at a single site.

Target Factory Cost

The direct capital cost of the target factory is given by

$$
c_{t f d}=c_{t f} v^{f} \text {, }
$$




\section{DISCLAIMER}

This report was prepared as an account of work sponsored by an agency of the United States Government. Neither the United States Government nor any agency thereof, nor any of their employees, makes any warranty, express or implied, or assumes any legal liability or responsibility for the accuracy, completeness, or usefulness of any information, apparatus, product, or process disclosed, or represents that its use would not infringe privately owned rights. Reference herein to any specific commercial product, process, or service by trade name, trademark, manufacturer, or otberwise does not necessarily constitute or imply its endorsement, recommendation, or favoring by the United States Government or any agency thereor. The views and opinions of authors expressed herein do not necessarily state or reflect those of the United States Government or any agency thereof. 
where $C_{t f}$ is the target factory cost coefficient, $v$ is the pulse rate $(H z)$, and $f$ is the scaling exponent. The base case parameters are $C_{t f}=\$ 0.1 \mathrm{~B}$ and $\mathrm{f}=0$. That is, we assume a constant direct capital cost of $\$ 0.1 \mathrm{~B}$. The effects of scaling with pulse rate are examined in the sensitivity studies describe later. There are currently no definitive studies on target factory costs; Eq. 4 is simply an estimate based on analogies to current facilities that mass produce precision products; e.g., semiconductor micro-chips.

\section{Driver Cost}

The cost of the heavy ion driver is based on an accelerator with the following characteristics: charge state $=+3$; ion mass $=$ $210 \mathrm{amu}$; emittance $=30 \mu \mathrm{m}-\mathrm{rad}$; ion kinetic energy $=10 \mathrm{GeV}$; number of beamlets $=8$; initial tune $=85^{\circ}$. The direct capital cost of the driver is given by

$C_{d d}=\left(0.32+0.088 E_{d}\right)\left(1.25+0.05 N_{C}\right)(1+0.0088(v-5)) \$ B$

where $E_{d}$ is the driver energy (MJ), $N_{C}$ is the number of chambers, and $v$ is driver pulse rate $(\mathrm{Hz})$. The first term is the cost of the high energy part of the accelerator, which increases linearly with driver energy. The second term includes additional costs for the low energy front end (25\%) and for the beam transport and final focusing ( $5 \%$ per chamber). The last term accounts fur the scaling of the cost with pulse rate. The cost increases by $4.4 \%$ for each $5 \mathrm{~Hz}$ above the base case pulse rate of $5 \mathrm{~Hz}$. Equation 5 gives driver costs that are consistent with the more detalled driver cost model developed by McDonnell Douglas. 6

Driver Efficiency

The efficiency of the driver is a function of both its energy and its pulse rate. Hovingh's data $^{7}$ (converted to charge state +3 ) is fit by the following expressions at $v=5$ and $10 \mathrm{~Hz}$ :

$$
\begin{aligned}
& n\left(E_{d}, 5\right)=0.208+0.0284 \ln \left(E_{d}-1.7\right), \text {, and } \\
& n\left(E_{d}, 10\right)=0.221+0.0273 \ln \left(E_{d}-1.7\right),
\end{aligned}
$$

where $E_{d}$ is in $M J$. At $10 \mathrm{~Hz}$ the efficiency is slightly higher. To scale to other pulse rates, the above equations are used in the following expression. 8

$$
n\left(E_{d}, v\right)=\frac{(1.55)(5 v) n\left(E_{d}, 5\right) n\left(E_{d}, 10\right)}{\left[10 n\left(E_{d}, 5\right)(v-5)\right]-\left[5 n\left(E_{d}, 10\right)(v-10)\right]}
$$

The factor of 1.55 converts the charge state +1 results to the charge state +3 case. That is, the $Q=3$ driver is a factor of 1.55 times more efficient than the $Q=1$ driver.

\section{Target Gain}

The target gain versus driver energy relationship used in our analysis is taken from Ref. 8. The following expression is used for 
the gain curve for single-shelled, cryogenic targets with a $r^{3 / 2} R$ parameter of 0.02 . [ $r$ is the focal radius $(\mathrm{cm})$ of the beam and $R$ is the range $\left(\mathrm{g} / \mathrm{cm}^{2}\right)$ of the ions.]

$$
G=20+157 \ln \left(E_{d} / 3.0\right),
$$

where $E_{d}$ is in $M J$. In our parametric studies, we looked at the effects of an advanced target design with improved performance. The advanced gain is given by a multiplier times G from Eq. 9 .

$$
G_{a d v}=2.56 G \exp \left(0.36 / E_{d}\right) \quad .
$$

\section{RESULTS DF PARAMETRIC STUDIES}

Parametric studies where carried out to examine the COE as a function of the driver pulse rate. We also examined the sensitivity of the results to variations from the reference case in the cost and performance models. The reference case was a single-unit plant with a constant net electric power of $1.0 \mathrm{GW}$. (Other reference case parameters are indicated in Table II.)

\section{Economy of Scale}

The COE as a function of the driver pulse rate is shown in Fig. 1 for the reference case power of $1.0 \mathrm{GW}_{\mathrm{e}}$ as well as for 0.5 and $1.5 \mathrm{GW}$ e plant. There are several things to note. First, and

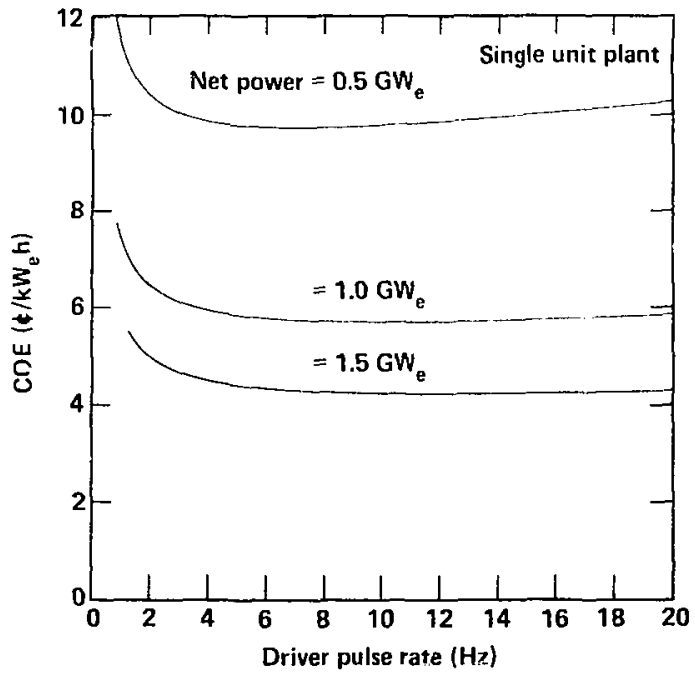

Fig. 1. Cost of electricity as a function of driver pulse rate for plants with net electric powers of $0.5,1.0$ and $1.5 \mathrm{GW}_{\mathrm{e}}$. 
most striking, is the stong economy of scale with increasing net electric power. The COE at $5 \mathrm{~Hz}$ is reduced by $41 \%$ (from 9.8 to $5.8 \mathrm{e} / \mathrm{kW}_{\mathrm{e}} \mathrm{h}$ ) when the net power is increased from 0.5 to $1.0 \mathrm{GW}_{\mathrm{e}}$. All of the curves show the same general shape; the COE initially decreases with increasing pulse rate and then goes through a broad, shallow minimum. The $C O E$ is insensitive to pulse rate above about 4 hz. For the $1.0 \mathrm{GW}_{\mathrm{e}}$ case, the optimum pulse rate is about $10 \mathrm{~Hz}$. The COE at $4 \mathrm{~Hz}$, however, is within $5 \%$ of the minimum. At 1.5 GW , the CUE is competitive with the projected COE from a coal-fired power plant $\left(4.4 \mathrm{~d} / \mathrm{kW}_{\mathrm{e}} \mathrm{h}\right) .4$

\section{Multi-unit Power Plants}

Figure 2 shows the $C O E$ as a function of the total net power for plants made up of different size units: $0.5,1.0$, and $1.5 \mathrm{GW}_{\mathrm{e}}$ net. A multi-unit power plant consists of a single oriver and target factory associated with more than one complete reactor units (1.e., chamber, structures, and balance of plant equipment). As indicated the COE decreases with increasing net power and with increasing unit size. The results shown here are all at a driver pulse rate of $5 \mathrm{~Hz}$ per unit.

The COE from a 1.0-GWe power plant consisting of t.wo $0.5-\mathrm{CW}_{\mathrm{e}}$ units is $6.4 \mathrm{e} / \mathrm{kW}_{\mathrm{e}} \mathrm{h}$. This is $10 \%$ higher than the COE from a single-unit power plant generating $1.0 \mathrm{GW}_{e}$. itence the

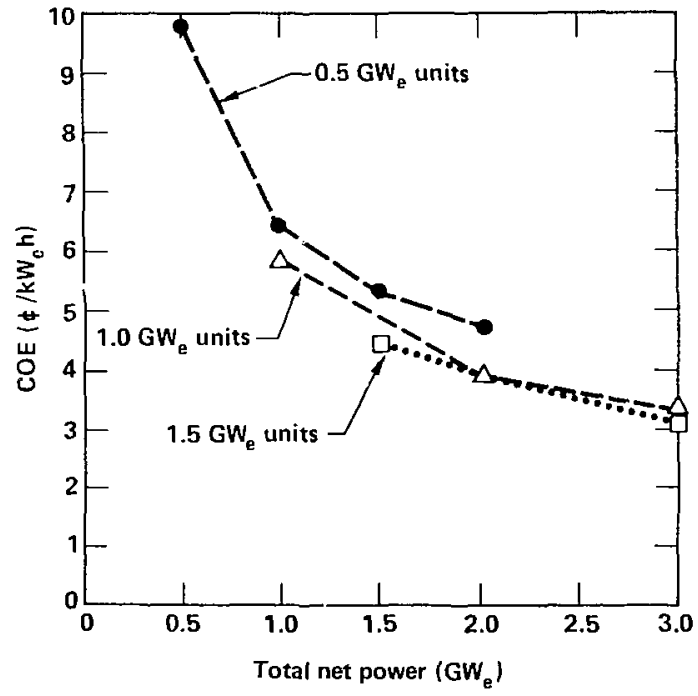

Fig. 2. Cost of electricity versus total net power for plants made up of different size units. 
multi-unit plant achieves most of the economy of scale benefits of the single unit plant. This is important since there may be other reasons for choosing a multi-unit plant (e.g., phased construction could more closely match load growth and spread out capital requirements). The single-unit plant has a reactor that is less expensive than the sum of the two smuller reactors due to the scaling given in Eq. 3. Also the two-unit plant has additional costs for beam transport and focusing. The COE for a four-unit, 2-GWe plant is $4.7 \mathrm{~d} / \mathrm{kW}_{\mathrm{e}} \mathrm{h}$ while a two-unit, $2 \mathrm{GW}_{\mathrm{e}}$ plant results in a COE of $3.9 \mathrm{e} / \mathrm{kW}_{\mathrm{e}}$. The $3 \mathrm{GW}$ plants at 3.0 and $3.3 \mathrm{E} / \mathrm{kW}_{\mathrm{e}} \mathrm{h}$ are competitive with the COE from future $1-\mathrm{GW}$ nuclear power plants $\left(3.5 \% / \mathrm{kW}_{\mathrm{e}} \mathrm{h}\right) .4$

The COE from the HIF plant is compared to cther fusion reactor studies in Table $I$. The costs from the other studies ${ }^{9-11}$ were inflated to January 1985 dollars, and the economic assumptions previously described were applied in all cases. That is, we used the same contingency, indirect cost factors, time-related cost factor, fixed charge rate, capacity factor, etc. As indicated, the COE projected for the $1200 \mathrm{MW}$ HIF plant using the Cascade reactor is 16 to $19 \%$ less than the COE for STARFIRE and MARS, respectively. Compared to HIBALL-II at $3784 \mathrm{MN}_{\mathrm{e}}$, the HIF/Cascade plant has a COE that is $33 \%$ lower.

Table I. Comparison of results with other fusion reactor studies. All cost are in constant 1985 dollars.

\begin{tabular}{|c|c|c|c|c|c|}
\hline & $\begin{array}{r}\text { Net P } \\
\text { STARFIRE }\end{array}$ & $\begin{array}{l}\text { er }=1 \\
\text { MARS }\end{array}$ & $\begin{array}{l}0 \mathrm{MW} \\
\text { HIF/CAS }\end{array}$ & $\begin{array}{l}\text { Net Power } \\
\text { HIBALL-II }\end{array}$ & $\begin{array}{l}3784 \mathrm{MN}_{\mathrm{e}} \\
\mathrm{HIF} / \mathrm{CAS}\end{array}$ \\
\hline Direct cost $(\$ B)$ & 2.07 & 2.24 & 1.83 & 4.80 & 3.43 \\
\hline Total cost $(\$ B)$ & 3.78 & 4.10 & 3.34 & 8.78 & 6.30 \\
\hline $\operatorname{COE}\left(\boldsymbol{E} / \mathrm{kW} \mathrm{e}^{\mathrm{h}}\right)$ & 6.13 & 6.33 & 5.14 & 4.59 & 3.07 \\
\hline
\end{tabular}

Other Parmameter Studies

The results of a sensitivity study, where we varied several parameters, are summarized in Table II. A $25 \%$ change in the driver cost results in a $13 \%$ change in the COE. A $25 \%$ change in the reactor cost leads to a $11 \%$ change in the $C D E$. The COE is insensitive to the reactor scaling exponent in Eq. 3 . If the target factory cost increases moderately with increasing pulse rate, the COE increases by $10 \%$ at $5 \mathrm{~Hz}$. (The selected normalization pulse rate of $1 \mathrm{~Hz}$ is, of course, arbitrary. If we had selected a higher pulse rate to normalize to, the sensitivity would be less.) Reducing the conversion efficiency to $35 \%$ increases the COE by $15 \%$. The advanced target gain curve, which at $4 \mathrm{MJ}$ gives a gain of 182 compared to 65 with the reference gain curve, leads to a $8 \%$ reduction in the COE. The economy of scale effects previously discussed are also indicated in the table and are seen to cause the largest effects. 
Table II. Changes in the COE ( $\star\left(\mathrm{kW}_{\mathrm{e}} \mathrm{h}\right)$ resulting from changes in the reference case parameters. The reference case COE is $5.84 \mathrm{~d} / \mathrm{kW}_{\mathrm{e}} \mathrm{h}$. The reference case parameters are given in square brackets. Fractional changes are given in parenthesis.

\begin{tabular}{|c|c|c|c|}
\hline Parameter & $\mathrm{COE}$ & Parameter & $\mathrm{COE}$ \\
\hline 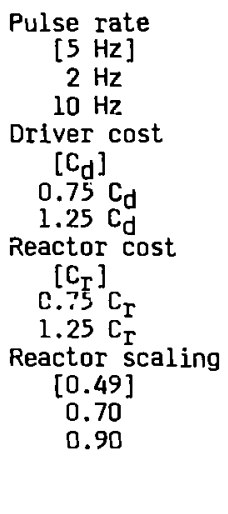 & $\begin{array}{l}6.5(+11 \%) \\
5.7(-2 \%)\end{array}$ & $\begin{array}{l}\text { T. F. scaling } \\
\text { [0] } \\
0.6 \\
\text { Conversion eff. } \\
\text { [54\%] } \\
45 \% \\
35 \% \\
\text { Target gain curve } \\
\text { [G] } \\
\text { Gadv } \\
\text { Net electric power } \\
\text { [1.0 GWe] } \\
0.5 \\
1.5 \\
\text { Units per plant } \\
{[1]} \\
2 \\
3\end{array}$ & $\begin{array}{l}5.4(-8 \%) \\
9.8(+68 \%) \\
4.4(-25 \%) \\
3.9(-33 \%) \\
3.3(-43 \%)\end{array}$ \\
\hline
\end{tabular}

CONCLUSIONS

We have examined the COE of HIF power plants in order to determine the economic impact of various design and system improvements. Our conclusions fall into three major areas: (1) optimum pulse rate, (2) economy of scale, and (3) various design improvements.

Optimum Pulse Rate

For the single-unit, 1-GW power plant, the optimum pulse rate (for both driver and chamber) is about $10 \mathrm{~Hz}$, resulting in a COE of $5.7 t / \mathrm{kW}_{\mathrm{e}} \mathrm{h}$. However, the COE is not very sensitive to pulse rate. For example, if the chamber pulse rate is limited to $4 \mathrm{~Hz}$, the COE increases by less than 5\%. This weak dependence of COE on pulse rate is important because major technological uncertainties are associated with predicting the maximum achievable chamber pulse rate.

\section{Economy of Scale}

As expected, the COE decreases with increasing net electric power. The reduction is significant, whether the power is increased by increasing the power of a single unit, or by using a single driver to operate several units. For a given net power, a multiunit plant achieves most of the economy-of-scale advantage of a 
single large plant. These savings result from the driver being such a large fraction of the plant cost. Only if the cost of the driver is significantly reduced will the penalty for small power units be slgnificantly affected. The HIF power plant can be competitive with coal or nuclear with a single unit $1.5 \mathrm{GW}$ plant or with multi-Init, 2-3 GW plants. The COE projected in these studies Indicate that the COE is 16 to $19 \%$ lower than from STARFIRE and MARS, and 33\% lower than from HIBALL-II.

\section{Various Deslgn Improvements}

Other than changing the net power of the plant, each of the variations we considered resulted in a change in the COE on the order of $10 \%$. To nlake dramatlc improvements in the COEs reported here will require a combinatlon of success in reducing costs and improving performance in a variety of areas.

\section{REFERENCES}

1. J. Hovingh, et al., The Cost of Induction Linac Drivers for Inertial Fusion for Various Target Ylelds, to be published in the proceedings of this meeting.

2. W. R. Meier and W. J. Hogan, ICF Reactor Economics: Identifying the High Leverage Design Features, Fusion Technol. E, 1820 (1985).

3. W. R. Meier and W. J. Hogan, Identifying Heavy-Ion-Beam Fusion Design and System Features with High Economic Leverage, LLNL. Report UCID-20470 (Mar. 1985).

4. J. G. Delene, et al., Nuclear Energy Cost Data Base - A Reference Data Base for Nuclear and Coal-Fired Porer Plant Power Generation Cost Analysis, U. S. Department of Energy Report, DOE/NE-0044/2 (March 1984).

5. I. Maya, et al., Final Report: Inertial Confinement Fusion Reaction Chamber and Power Conversion System Study, GA Technologies Report GA-Al7842 (oct. 1985).

6. D. S. Zuckerman, et al., Performance and Cost Modeling of a Linac-Driven HIF Power Piant, to be published in the proceedings ofg this meeting.

7. J. Hovingh, LLNl, private communication (Jan. 1986).

8. J. D. Lind1, J. W-K. Mark, Recent Livermore Estimates of the Energy Gain of Cryogenic Single-Shell Ion Beam Targets, Laser and Particle Beams, 3, 37 (1985).

9. c. C. Baker, et al., "STARFIRE - A Commercial Tokamak Fusion Power Plant Study, Argonne National Laboratory Report ANL/FPP-80-1 (Sept. 1980).

10. B. G. Loagan, et al., MARS - Mirror Advanced Reactor Study, LLNL Report UCRL-53480 (June 1984).

11. B. Badger, et al., HIBALL-II - An Improved Conceptual Heavy Ion Fusion Reactor Study, Univiversity of Wisconsin Report UWFDM-625 (Dec. 1984). 